\title{
The Influence of Amplitude- and Frequency-Dependent Stiffness of Rail Pads on the Random Vibration of a Vehicle-Track Coupled System
}

\author{
Kai Wei, ${ }^{1,2}$ Pan Zhang, ${ }^{1,2}$ Ping Wang, ${ }^{1,2}$ Junhua Xiao, $^{3}$ and Zhe Luo ${ }^{4}$ \\ ${ }^{1}$ MOE Key Laboratory of High-Speed Railway Engineering, Chengdu 610031, China \\ ${ }^{2}$ School of Civil Engineering, Southwest Jiaotong University, Chengdu 610031, China \\ ${ }^{3}$ MOE Key Laboratory of Road and Traffic Engineering, Tongji University, Shanghai 201804, China \\ ${ }^{4}$ Department of Civil Engineering, University of Akron, Akron, OH 44325, USA \\ Correspondence should be addressed to Ping Wang; 392173023@qq.com
}

Received 4 February 2016; Revised 18 April 2016; Accepted 17 May 2016

Academic Editor: Ivo Caliò

Copyright (C) 2016 Kai Wei et al. This is an open access article distributed under the Creative Commons Attribution License, which permits unrestricted use, distribution, and reproduction in any medium, provided the original work is properly cited.

\begin{abstract}
The nonlinear curves between the external static loads of Thermoplastic Polyurethane Elastomer (TPE) rail pads and their compressive deformations were measured. A finite element model (FEM) for a rail-fastener system was produced to determine the nonlinear compressive deformations of TPE rail pads and their nonlinear static stiffness under the static vehicle weight and the preload of rail fastener. Next, the vertical vehicle-track coupled model was employed to investigate the influence of the amplitudeand frequency-dependent stiffness of TPE rail pads on the vehicle-track random vibration. It is found that the static stiffness of TPE rail pads ranges from 19.1 to $37.9 \mathrm{kN} / \mathrm{mm}$, apparently different from the classical secant stiffness of $26.7 \mathrm{kN} / \mathrm{mm}$. Additionally, compared with the nonlinear amplitude- and frequency-dependent stiffness of rail pads, the classical secant stiffness would not only severely underestimate the random vibration acceleration levels of wheel-track coupled system at frequencies of $65-150 \mathrm{~Hz}$ but also alter the dominant frequency-distribution of vehicle wheel and steel rail. Considering that these frequencies of $65-150 \mathrm{~Hz}$ are the dominant frequencies of ground vibration accelerations caused by low-speed railway, the nonlinear amplitude- and frequencydependent stiffness of rail pads should be taken into account in prediction of environment vibrations due to low-speed railway.
\end{abstract}

\section{Introduction}

Urban railway traffic influences the environment by emissions of ground-borne vibration $(1-80 \mathrm{~Hz})$ and structureborne noise $(16-250 \mathrm{~Hz})$. Vibrations and noises can sometimes reach such a high level that can hardly be tolerated by neighboring residents especially in heavily populated urban environments. Consequently, the issue of train-induced vibration has received increasing attention, particularly as people become more aware of environmental issues. Moreover, as new lines are proposed, noise and vibration are important aspects that require careful consideration in the planning stage and often form the basis of objections to new rail development.

Numerous efforts have been made to accurately predict environmental vibration and noise generated by urban railway. Nielsen et al. presented a hybrid model for the prediction of ground-borne vibration due to discrete wheel and rail irregularities [1]. Triepaischajonsak and Thompson also introduced a hybrid modelling approach to study the sleeperpassing effect [2]. It is found that the sleeper-passing effect is less significant than excitation due to track unevenness. Kouroussis et al. used a numerical prediction approach to investigate the main parameters affecting ground vibration during the passing of trams in Brussels and found that the calculated high ground vibrations stem from singular rail surface defects [3]. Discontinuous irregularities have been shown to cause a significant increase in vibration in comparison to a smooth track [4]. Hung et al. established a $2.5 \mathrm{D}$ finite/infinite element model to simulate the soil vibrations caused by subway trains [5], and they concluded that velocity and acceleration responses of the soil are largely 
amplified due to the presence of rail irregularity. Liu and Zhai investigated vertical dynamic wheel/rail interaction resulting from a polygonal wheel, and they found that influence of outof-round wheel is mainly related to the wheelset vibration [6]. According to the previous experiences, the wheel vibration levels have close relation with environment vibration and noise. $\mathrm{Li}$ et al. presented a numerical procedure for the simulation of the concrete bridge-borne low-frequency noise caused by the coupled vibration of a train-track-bridge system. One of the conclusions is that the dominant frequency range for trains traveling between 50 and $80 \mathrm{~km} / \mathrm{h}$ is primarily attributable to random rail roughness and dynamic characteristics of both the bridge and track structure [7].

As stated previously, the dynamic component of the vertical wheel-rail contact force due to out-of-round wheels and rail irregularities is an important source of ground vibration and structure-borne noise. This is especially true when the design speed of railway is below the wave velocities in the soil, such as a subway or tram, where the free-field response can be dominated by the dynamic loads $[8,9]$. Thus, the precision of the forecasted ground vibration and structure-borne noise induced by low-speed urban railway primarily depends on the accurate prediction of random dynamic loads of vehicle-track coupled system.

In recent decades, a large proportion of models and algorithms have been introduced and developed to calculate the dynamic random loads of a vehicle-track coupled system. In general, a vehicle-track coupled model is composed of a vehicle model, a track model, and a wheel-track coupled relation. The vehicle model has evolved from a multibody model $[10,11]$ of a mass-spring system to a solid finite element model (FEM) $[12,13]$. The multibody model is easy to understand, and its accuracy can meet the engineering requirements. The solid finite element model can be used to show the vibration characteristics of the detail structures, but its computation efficiency is low. The track models have been developed from the classical finitely long models to the infinitely long models, such as Symplectic Method [14-16]. An FEM of a nonballasted track $[17,18]$ and a discrete element model (DEM) of a ballasted track have also been proposed [19, 20]. In the wheel/rail coupled relations, the nonlinear Hertz contact model is universally used to calculate the wheel/rail normal force, and the classical linear Kalker contact model or the nonlinear Shen-Hedrick-Elkins contact model is also often employed to compute the wheel/rail creep force [21, 22]. In addition, some simple linear wheel/rail coupled relations are also proposed, such as a 2D linear Hertz spring model [23] and a 3D linear wheel/rail interaction model [24]. After establishment of the abovementioned models, a series of the numerical integration algorithms in time-space domain $[10,16]$ or the theoretical analytical methods in the frequencywavenumber domain $[15,25]$ can be adopted for calculation of the random vibration responses of a vehicle-track coupled system.

Although there have been a large number of vehicletrack coupled models and the corresponding algorithms, there remains a discrepancy between the predicted and measured vibration responses for a vehicle-track coupled system, especially in the frequency domain. The problem probably is related to the calculation parameters used in the vehicle-track coupled models. In a vehicle-track coupled system, there are inevitably polymer materials for vibration attenuation, such as rail pads, under sleeper pads [26, 27], and bed pads [28, 29]. The parameters of these polymer materials have a close relation with the environmental temperature, the frequency of external loads, and the amplitude of external loads [3032]. A great quantity of experimental results demonstrate that the dynamic stiffness of polymer materials enhances with the decrease of temperature or with the increase of frequency. However, the variation of dynamic stiffness of polymer materials with load amounts still remains under debate. For example, one study [31] found that the stiffness of rail pads decreases as the load amount increases, while another study [33] found that the stiffness of rail pads increases as the load amount increases; this discrepancy undoubtedly results from the chemical compositions of the polymer rail pads used in the two studies.

In recent years, the influence of the frequency- and amplitude-dependent dynamic parameters of polymer materials in vehicle-track coupled system has been investigated. However, there are still some unsolved issues. Wei et al. used a frequency-domain algorithm of vehicle-track coupled system and the existing experimental results of frequency-dependent stiffness of rail pads to investigate the influence of frequencydependent stiffness of rail pads on the frequency-domain distribution of vibrations created by subway in the frequency range of $0 \sim 200 \mathrm{~Hz}$ [34]. In this study, the amplitudedependent characteristics of rail pads were neglected. Zhu et al. implemented a nonlinear and fractional derivative viscoelastic (FDV) model into the time-domain dynamic analysis of coupled vehicle-slab track (CVST) systems [35]. Apart from the low calculation efficiency of the time-domain model, considering the proposed model was verified only by the experiments with low-frequency loads (less than $10 \mathrm{~Hz}$ ), the difference between the proposed model and the ordinary model in high-frequency domain (more than $10 \mathrm{~Hz}$ ) is worthy of further research. Thus, it is necessary to comprehensively and efficiently consider the frequencyand amplitude-dependent dynamic parameters of polymer materials in a vehicle-track coupled system.

For the purpose of investigation into the effect of the nonlinear amplitude- and frequency-dependent dynamic stiffness of rail pads on the frequency-domain random vibration responses of vehicle-track coupled system, the rail pads of Thermoplastic Polyurethane Elastomer (TPE) typically used in Chinese subway fasteners were chosen as the focus of this study. Firstly, the nonlinear curves between the static loads of TPE rail pads and their corresponding compressive deformations were measured with the universal testing machine (Section 2). Secondly, a finite element model (FEM) applied for nonlinear static analysis of a rail-fastener system was established to calculate the compressive deformations of TPE rail pads and their corresponding static stiffness under the static vehicle weight and the preload of rail fastener (Section 3). Finally, based on the nonlinear static results of the rail-fastener system, the vertical vehicle-track coupled model was employed to investigate the influence of the nonlinear amplitude- and frequency-dependent stiffness of TPE rail 


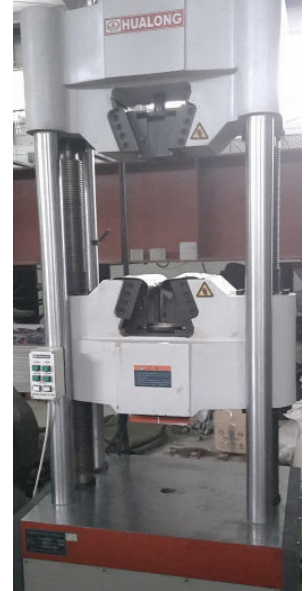

(a)

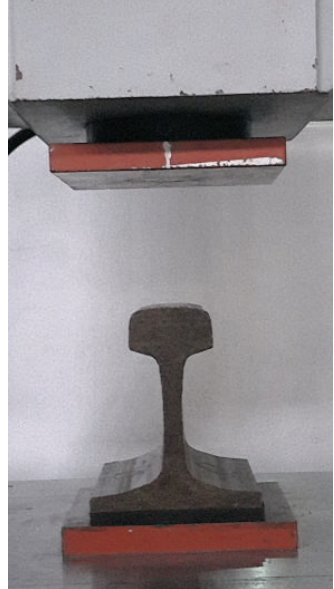

(b)
FIGURE 1: Load testing of TPE rail pads: (a) universal testing machine and (b) test setup.

pads on the random vibration in a vehicle-track coupled system (Section 4).

\section{Amplitude-Dependent Stiffness of Rail Pads}

The nonlinear curves between the static loads of TPE rail pads and their corresponding compressive deformations were measured with a universal testing machine (Figure 1(a)) at an ambient temperature of $25^{\circ} \mathrm{C}$.

2.1. Experimental Procedure. First, a piece of the prototype TPE rail pad was installed between the loading plate of universal testing machine and the bearing plate (Figure 1(b)). In order to ensure the uniform loading on the surface of rail pad, a section of $60 \mathrm{~kg} / \mathrm{m}$ steel rail longer than the test pad was placed on the surface of rail pad. Next, the test pad was preloaded twice or more times prior to the start of the test so as to eliminate experimental error. According to the stipulations in Chinese standard [36], the preload should be more than the maximum static load on a piece of rail pad in service. Considering the sharing support by the neighboring fasteners, the maximum static load on a piece of rail pad is generally less than $1 / 8$ of the vehicle weight. In view of Chinese "Type A" subway vehicle weight of $640 \mathrm{kN}$ (where 1/8 of the vehicle weight is equivalent to $80 \mathrm{kN}$ ), the preload was set to a minimum of $100 \mathrm{kN}$ in this test. Following completion of the preloading, a piece of TPE rail pad was loaded from $0 \mathrm{kN}$ to $90 \mathrm{kN}$ with the loading rate of $3 \mathrm{kN} / \mathrm{s}$ [36], and the load-deformation curve of the test pad was recorded.

The procedure outlined above represents the test procedure for a single piece of TPE rail pad. In this research, a total of three pieces of TPE rail pads were measured to minimize the experimental error from a single piece of rail pad.

2.2. Experimental Results. A load-deformation curve was obtained from each of the three TPE specimens. In order to eliminate experimental error, the three load-deformation

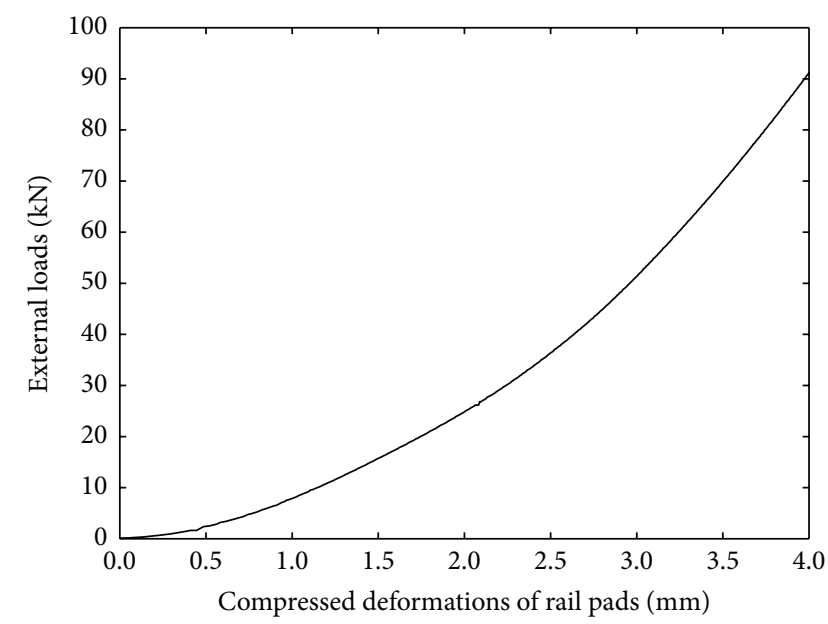

FIgure 2: The average load-deformation curve of three TPE rail pads.

curves were averaged; the resulting load-deformation curve is shown in Figure 2. It is clear that the relationship between the external loads and the corresponding deformations of the test pad is nonlinear.

2.2.1. The Linear Constant Static Stiffness of Rail Pads. In previous research, the static stiffness of rail pads was simply regarded as the linear secant stiffness, which can be calculated with

$$
K=\frac{F_{2}-F_{1}}{S_{2}-S_{1}}
$$

where $F_{1}$ is the preload of two springs in a fastener system (generally about $20 \mathrm{kN}$ in Chinese subway fasteners), $S_{1}$ is the compressive deformation of rail pads under $F_{1}, F_{2}$ is the total loads involving the vehicle weight and the preload of two springs in a fastener system, and $S_{2}$ is the compressive deformation of rail pads under $F_{2}$. However, it is apparent that the linear secant stiffness of rail pads will not be applicable to the rail pads with the strong nonlinear stiffness.

2.2.2. The Nonlinear Amplitude-Dependent Static Stiffness of Rail Pads. In order to accurately obtain the variation of the static stiffness of the test pads with the external load amounts, the load-deformation curve in Figure 2 was fitted with a quartic equation (see (2)), and then the first-order derivative of the fitting equation (2) is computed (i.e., (3)). As shown in (3), the relation between the static stiffness and the compressive deformation of TPE rail pads is also nonlinear:

$$
\begin{aligned}
& F=0.0401 S^{4}+0.1228 S^{3}+3.368 S^{2}+5.021 S-0.4518 \\
& K=0.1604 S^{3}+0.3684 S^{2}+6.736 S+5.021
\end{aligned}
$$

where $F$ is the external load, $K$ is the nonlinear amplitudedependent static stiffness of rail pads, and $S$ is the compressive deformation of rail pads. According to (3), it is easy to draw the stiffness-deformation curve of TPE rail pads, as 


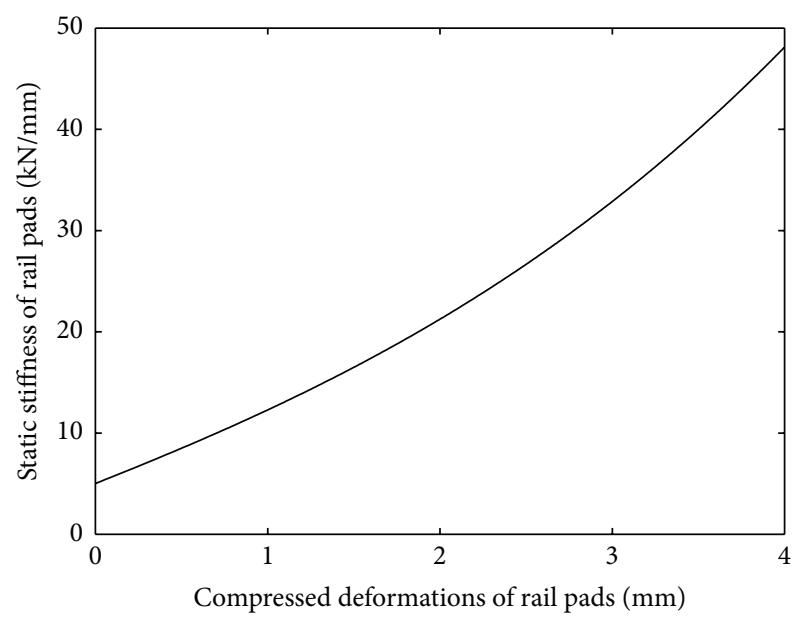

FIgURE 3: The stiffness-deformation curve of TPE rail pads.

shown in Figure 3. It can be observed from Figure 3 that the static stiffness of rail pads increases with the compressive deformation and the rate of increase also gradually increases.

\section{Nonlinear Static Analysis of Rail-Fastener System}

According to the test results presented in Section 2, the stiffness of a TPE rail pad depends on its compressive deformation under the vehicle weight and the preload of rail fastener. Therefore, the nonlinear static analysis of railfastener system should be firstly conducted to determine the compressive deformation of rail pad and its corresponding static stiffness before investigating the random vibration of the vehicle-track coupled system.

3.1. Nonlinear Static FEM of Rail-Fastener System. The nonlinear static FEM of the rail-fastener system was established by using commercial software (ANSYS). In this FEM model, a steel rail of $60 \mathrm{~kg} / \mathrm{m}$ with fasteners installed at the interval of $0.6 \mathrm{~m}$ was simulated using Beam4 and Combin39 elements in ANSYS, respectively. Combin39 elements are capable of simulating the nonlinear relation between the loads and the deformations. The vertical stiffness of a rail-fastener system is composed of the spring stiffness and the pad stiffness. Since the spring stiffness is only $0.5 \sim 1.2 \mathrm{kN} / \mathrm{mm}$, the stiffness of the rail pad can be approximately regarded as the stiffness of the entire fastener system. Thus, according to the nonlinear relationship between the external loads and the compressive deformations of rail pads, Combin39 elements were used to simulate the nonlinear mechanical behavior of the entire fastener system.

In the nonlinear static analysis, the loads imposed on a rail involved the rail weight $(60 \mathrm{~kg} / \mathrm{m})$, the preload on each fastener $(20 \mathrm{kN})$, and the half of vehicle weight $(320 \mathrm{kN})$. The distance between the four wheels is listed in Table 1.

3.2. Nonlinear Static Results of Rail-Fastener System. Based on the nonlinear static results of the FEM for the rail-fastener
TABLE 1: The parameters of Chinese "Type A" subway vehicle.

\begin{tabular}{lc}
\hline Parameters & Magnitude \\
\hline Mass of vehicle body $M_{c} /(\mathrm{kg})$ & 38500 \\
Mass of vehicle bogie $M_{t} /(\mathrm{kg})$ & 2980 \\
Mass of vehicle wheelset $M_{w} /(\mathrm{kg})$ & 1350 \\
The moment of inertia of vehicle body $J_{c} /\left(\mathrm{kg} \cdot \mathrm{m}^{2}\right)$ & $2.5 \times 10^{6}$ \\
The moment of inertia of vehicle bogie $J_{t} /\left(\mathrm{kg} \cdot \mathrm{m}^{2}\right)$ & $3.6 \times 10^{3}$ \\
The stiffness and of the primary suspension & $2.1 \times 10^{6}$ \\
$K_{\mathrm{pz}} /\left(\mathrm{N} \cdot \mathrm{m}^{-1}\right)$ & \\
The damping of the primary suspension & $4.9 \times 10^{4}$ \\
$C_{\mathrm{pz}} /\left(\mathrm{N} \cdot \mathrm{S} \cdot \mathrm{m}^{-1}\right)$ & \\
The stiffness of the secondary suspension & $2.5 \times 10^{6}$ \\
$K_{\mathrm{sz}} /\left(\mathrm{N} \cdot \mathrm{m}^{-1}\right)$ & \\
The damping of the secondary suspension & $2.0 \times 10^{5}$ \\
$C_{\mathrm{sz}} /\left(\mathrm{N} \cdot \mathrm{S} \cdot \mathrm{m}^{-1}\right)$ & \\
The length between two bogie centers in a & 18 \\
vehicle $/(\mathrm{m})$ & 2.4 \\
The vehicle wheelbase/(m) &
\end{tabular}

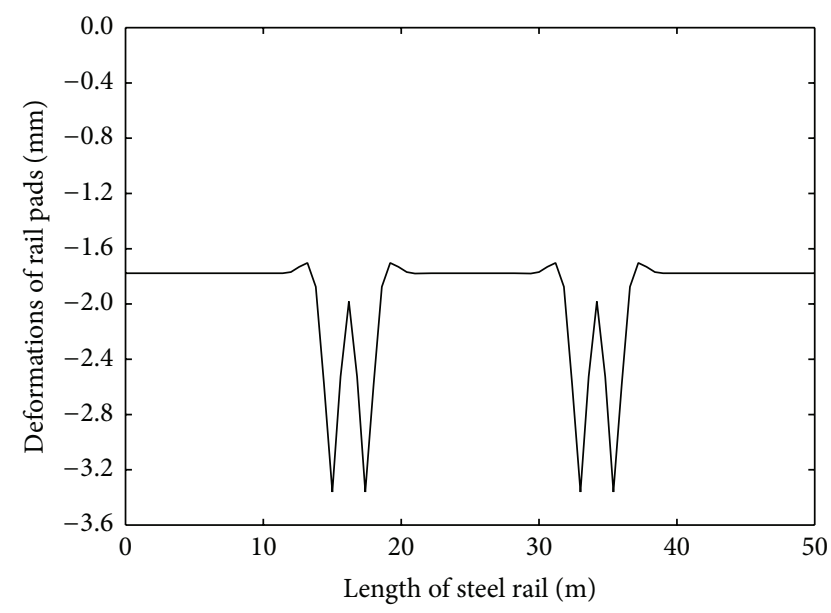

FIgURE 4: The compressive deformations of TPE rail pads at the different positions of a rail under a rail-fastener preload of $20 \mathrm{kN}$ and the half of vehicle weight $(320 \mathrm{kN})$.

system, the compressive deformations of TPE rail pads at the various positions of a rail under the preload of the fasteners and the half of vehicle weight are shown in Figure 4.

It can be observed from Figure 4 that a load equivalent to $1 / 8$ of the vehicle weight only influences the compressive deformations of three groups of the neighboring TPE rail pads before and after loading by a single vehicle wheel, and the mutual interference of the two bogies can be disregarded. In addition, it can be found from the calculated results that the compressive deformations of TPE rail pads under a fastener preload of $20 \mathrm{kN}$ are $1.8 \mathrm{~mm}$ which corresponds to a static stiffness of $19.1 \mathrm{kN} / \mathrm{mm}$. After one half of the vehicle weight is imposed on a rail, the maximum compressive deformation of TPE rail pads becomes $3.4 \mathrm{~mm}$; this deformation corresponds to a static stiffness of $37.9 \mathrm{kN} / \mathrm{mm}$, which reflects an increase by about $98 \%$ as compared to the static stiffness of TPE rail pads under fastener preload. However, the linear 
TABLE 2: The parameters of the monolithic nonballasted track.

\begin{tabular}{lcc}
\hline Components of track & Parameters & Magnitude \\
\hline \multirow{3}{*}{ Steel rail } & Young's modulus $E_{r} /\left(\mathrm{N} \cdot \mathrm{m}^{-2}\right)$ & $2.06 \times 10^{11}$ \\
& Area moment of inertia $I_{r} /\left(\mathrm{m}^{4}\right)$ & $3.22 \times 10^{-5}$ \\
\hline The mass in one meter $m_{r} /\left(\mathrm{kg} \cdot \mathrm{m}^{-1}\right)$ & 60.64 \\
\hline & The stiffness $K_{p} /\left(\mathrm{N} \cdot \mathrm{m}^{-1}\right)$ & Variation with amounts and the frequencies of loads \\
& The damping $C_{p} /\left(\mathrm{N} \cdot \mathrm{S} \cdot \mathrm{m}^{-1}\right)$ & $7.5 \times 10^{4}$ \\
\hline
\end{tabular}

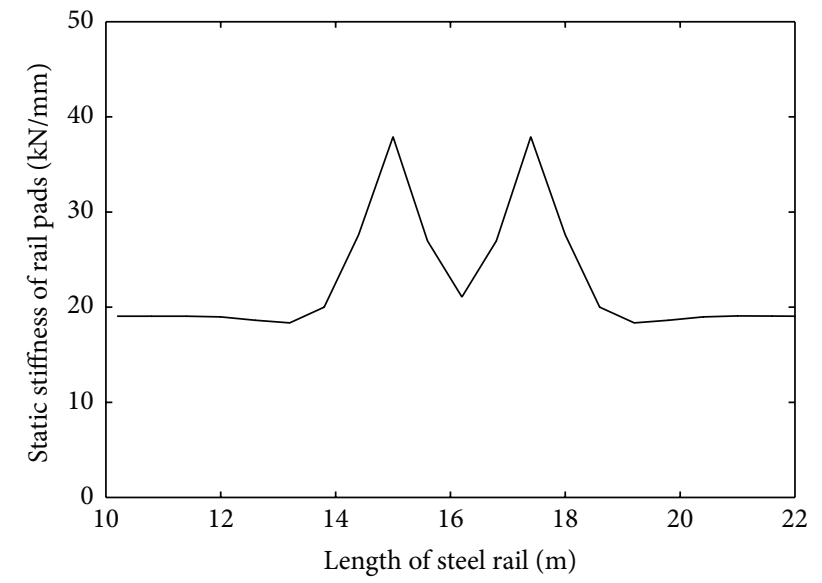

FIgure 5: The static stiffness of TPE rail pads at different positions under a bogie.

secant stiffness of TPE rail pads computed with (1) is only $26.7 \mathrm{kN} / \mathrm{mm}$, which is apparently not equal to the actual nonlinear stiffness. Therefore, the linear secant stiffness of TPE rail pads cannot accurately reflect the nonlinear variation of static stiffness with the external load amounts.

In light of the fact that the compressive deformations of TPE rail pads under any one bogie will essentially have the same distribution (see Figure 4), it is sufficient to only demonstrate the corresponding stiffness of TPE rail pads at different positions under a bogie, as shown in Figure 5. According to the calculated results in Figure 5, it is possible to ascertain the static stiffness of rail pads in a vehicle-track coupled model.

\section{Influence of the Nonlinear Amplitude- and Frequency-Dependent Stiffness on the Random Vibration of a Vehicle-Track Coupled System}

4.1. The Vertical Vehicle-Track Coupled Model and the Key Parameters. The vertical vehicle-track coupled model applied for calculation of the random vibration of the vehicletrack system due to track irregularity has been reported by Wei et al. [34]. In this model, the whole vehicle can be modelled as the one with two suspensions, involving the up-and-down and nodding movement of vehicle body and bogies and the vertical movement of four wheels, for a total of 10 freedom degrees (Figure 6). The distance among the four

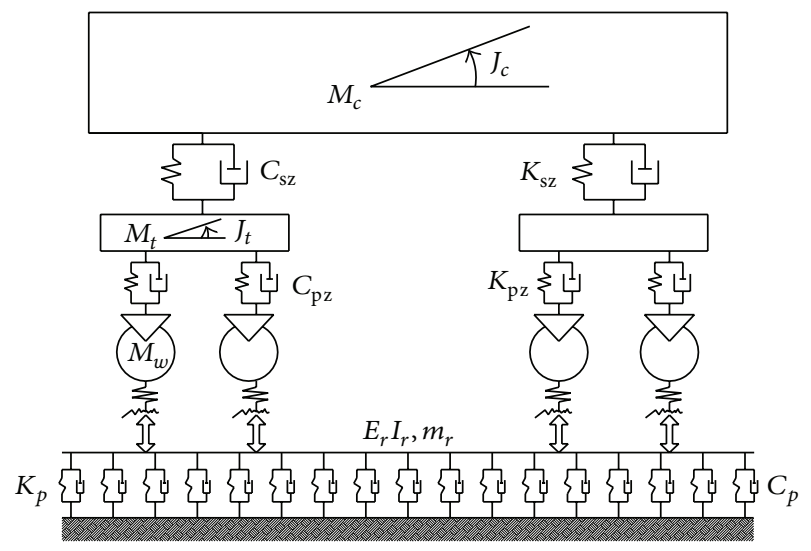

Figure 6: Vehicle-track coupled dynamic model.

wheels and the key parameters of vehicle are listed in Table 1. The rail can be regarded as an Euler beam supported by the discrete fasteners with the interval spacing of $0.6 \mathrm{~m}$. Due to the rigid connection between the sleeper and the bed and the big mass of the monolithic concrete bed, the bottom of rail fastener can be approximately simulated as a fixed constraint (Figure 6). The key parameters of track are in Table 2.

Additionally, in the vertical vehicle-track coupled model, the linear wheel/rail contact stiffness $K_{h}$ is used to calculate the vertical wheel/rail contact force. The linear wheel/rail contact stiffness $K_{h}$ can be derived by (4) (8):

$$
p(t)=\left[\frac{1}{G} \Delta Z(t)\right]^{3 / 2}
$$

where $p(t)$ is wheel/rail contact force $(\mathrm{N}), G$ is a wheel/rail contact constant $\left(\mathrm{m} / \mathrm{N}^{2 / 3}\right)$, and $\Delta Z(t)$ is elastic compression between wheel and rail $(\mathrm{m})$. This compression value is composed of the static wheel/rail compression $\Delta Z_{j 0}(t)$ and the wheel/rail relative deformation $\Delta Z_{j w r}(t)$, as shown in

$$
\begin{aligned}
\Delta Z(t) & =\Delta Z_{j 0}(t)+\Delta Z_{j w r}(t) \\
\Delta Z_{j 0}(t) & =G P_{0}^{2 / 3} \\
\Delta Z_{j w r}(t) & =Z_{w j}(t)-Z_{r}\left(x_{G j}, t\right)-Z_{j 0}(t) .
\end{aligned}
$$


In (6), $P_{0}$ is static wheel load $(\mathrm{N})$, which is half of static axle load. Then, the dynamic wheel/rail force can be obtained with application of

$$
\begin{aligned}
P_{j w r}(t) & =P_{j}(t)-P_{0} \\
& =\left[\frac{1}{G}\left(\Delta Z_{j 0}+\Delta Z_{j w r}(t)\right)\right]^{3 / 2}-P_{0} \\
& =\left[P_{0}^{2 / 3}+\frac{1}{G} \Delta Z_{j w r}(t)\right]^{3 / 2}-P_{0} .
\end{aligned}
$$
in

Thus, the linear wheel/rail contact stiffness $K_{h}$ is as shown

$$
\begin{aligned}
K_{h} & =\frac{\partial P_{j w r}}{\partial \Delta Z_{j w r}}=\left.\frac{3}{2}\left[P^{2 / 3}+\frac{1}{G} \Delta Z_{j w r}\right]^{1 / 2}\left[\frac{1}{G}\right]\right|_{\Delta Z_{j w r}=0} \\
& =\frac{3}{2} \frac{1}{G} P^{1 / 3}
\end{aligned}
$$

In the dynamic analysis, there is no relative movement between vehicle and track, only irregularity movement of the track. The positions between the vehicle wheels and the rail fasteners in the vertical vehicle-track coupled model are the same as those in the nonlinear static analysis of the rail-fastener FEM (Section 3). The simulated train speed is $80 \mathrm{~km} / \mathrm{h}$, and the vertical track irregularity consists of the 6 th grade of the classical vertical track irregularity spectra of American Federal Railroad Administration (FRA) [37] (in which the simulated wave lengths are 1 100 $\mathrm{m}$ ) and the vertical short-wave measured track irregularity spectra of Chinese railway between Shijiazhuang Station and Taiyuan Station that is shown in (10) below (in which the simulated short wavelengths are $0.1 \sim 1 \mathrm{~m})$. In $(9), W(x)$ is power spectral density (PSD) of the vertical short-wave track irregularity (unit: $\mathrm{mm}^{2} / \mathrm{m}^{-1}$ ) and $x$ is the spatial frequency of the track irregularity (unit: $1 / \mathrm{m}$ ):

$$
W(x)=0.036 x^{-3.15}
$$

4.2. The Relation between the Stiffness of Rail Pads, the Amounts, and the Frequencies of External Loads. Based on the experimental results obtained in other studies [30, 38, 39], it has been found that the dynamic stiffness of rail pads is closely linear with the frequencies of external loads under the logarithmic coordinate [34], as shown in

$$
\log _{10}^{K}=k \times\left(\log _{10}^{f}-\log _{10}^{f_{0}}\right)+\log _{10}^{K_{0}}
$$

In (10), $K$ is the dynamic stiffness of rail pads at a frequency of $f, K_{0}$ is the initial dynamic stiffness of rail pads at the lower frequency of $f_{0}$, and $k$ is the slope of the linear relation between the dynamic stiffness of rail pads and the frequencies of external loads under the logarithmic coordinate. The index of $k$ ranges from 0.05 to $0.3[30,38,39]$ and represents the extent of variation in the dynamic stiffness of the rail pads with the frequencies of external loads. The initial dynamic stiffness of $K_{0}$ at the lower frequency of
TABLE 3: The calculation cases.

\begin{tabular}{lcc}
\hline Case & $K_{0} / K_{0}(S)$ & $k$ \\
\hline 1 & $1.4 \times 26.7 \mathrm{kN}=37.4 \mathrm{kN}$ & 0 \\
2 & $1.4 \times 26.7 \mathrm{kN}=37.4 \mathrm{kN}$ & 0.15 \\
3 & $1.4 \times(19.1 \sim 37.9 \mathrm{kN})=26.7 \sim 53.1 \mathrm{kN}$ & 0.15 \\
\hline
\end{tabular}

$f_{0}$ depends on the compressive deformations of rail pads induced by external loads. Thus, (10) should be modified into

$$
\log _{10}^{K}=k \times\left(\log _{10}^{f}-\log _{10}^{f_{0}}\right)+\log _{10}^{K_{0}(S)},
$$

where $K_{0}(S)$ is the initial dynamic stiffness of rail pads related to their compressive deformations at the lower frequency of $f_{0}$. In general, the dynamic stiffness of Chinese subway rail pads is less than 1.4 times their static stiffness at frequencies of $3 \sim 5 \mathrm{~Hz}$. Therefore, combined with the static stiffness of TPE rail pads in Figure 5, the initial dynamic stiffness of TPE rail pads can be approximately estimated with a ratio of $1.4: 1$ between dynamic stiffness and static stiffness at $4 \mathrm{~Hz}$.

In order to compare the influence of the linear secant stiffness, the nonlinear frequency-dependent stiffness, and the nonlinear amplitude- and frequency-dependent stiffness of rail pads on random vibration of a vehicle-track coupled system, three calculation cases were designed on basis of the nonlinear static results of the rail-fastener system, as shown in Table 3.

In Case 1, the dynamic stiffness of all rail pads in the vehicle-track coupled model is considered to be 1.4 times the linear secant static stiffness calculated with (1), regardless of the nonlinear amplitude- and frequency-dependent characteristics of rail pads. In Case 2, the frequency-dependent dynamic stiffness of all rail pads in the vehicle-track coupled model is considered in accordance with (5) in which 1.4 times the linear secant static stiffness of rail pads is taken as the approximate initial dynamic stiffness of rail pads at a low frequency of $4 \mathrm{~Hz}$, without regard of the amplitudedependent characteristics of rail pads. In Case 3, (6) is used for comprehensive consideration of the amplitude- and frequency-dependent dynamic stiffness of rail pads, and the initial dynamic stiffness of rail pads at the low frequency of $4 \mathrm{~Hz}$ is 1.4 times the nonlinear static stiffness of rail pads (as shown in Figure 5) in the vehicle-track coupled model.

Considering that the study was mainly focused on the influence of the amplitude-dependent stiffness of rail pads on the random vibration of a vehicle-track coupled system, $k$ is uniformly defined as 0.15 in Cases 2 and 3.

4.3. Effect of the Stiffness of TPE Rail Pads on Random Vibration of a Vehicle-Track Coupled System. According to the designed cases listed in Table 3, the vertical random vibration of a vehicle body, bogie, wheel, and rail is calculated. The resulting vibrations of each of these structures are shown in Figures 7-10.

4.3.1. PSD of the Vertical Random Vibration Acceleration of a Vehicle Body. It can be observed from Figure 7 that the calculated dominant frequency domain of vehicle body 


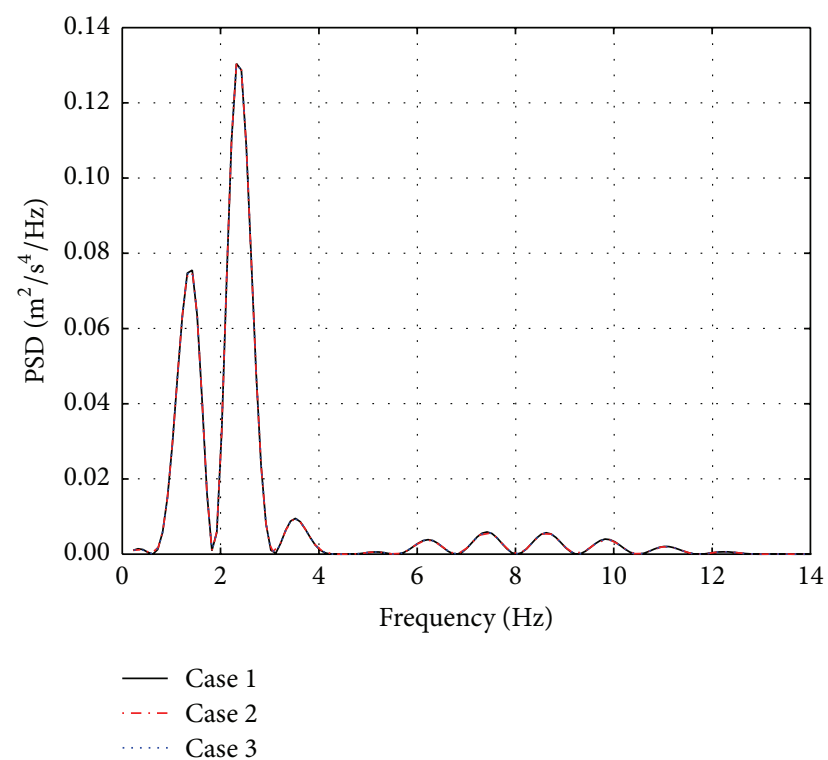

Figure 7: Power spectral density (PSD) of the vertical random vibration acceleration of a vehicle body due to the linear secant stiffness, the nonlinear frequency-dependent stiffness, and the nonlinear amplitude- and frequency-dependent stiffness of rail pads.

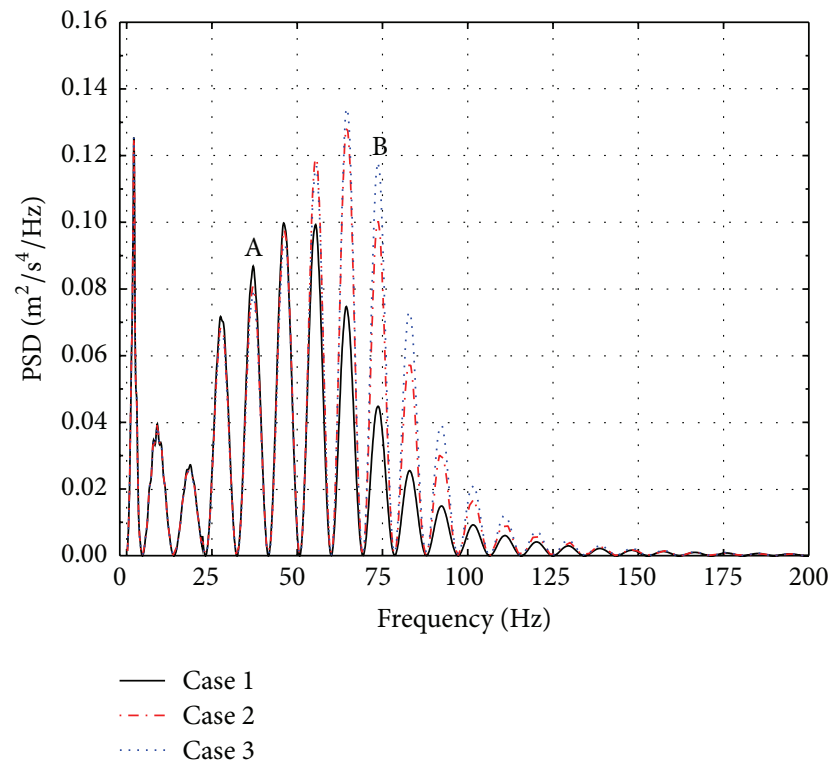

FIgURE 8: Power spectral density (PSD) of the vertical random vibration acceleration of a vehicle bogie due to the linear secant stiffness, the nonlinear frequency-dependent stiffness, and the nonlinear amplitude- and frequency-dependent stiffness of rail pads.

in this paper accords with the summary about the actual vibration generated by railway in [40].

It is also found from Figure 7 that the vertical random vibration responses of vehicle body are identical among the three cases, which demonstrates that the influence of the variation of the stiffness of rail pads on the random vibration of vehicle body is very small and thus can be ignored.

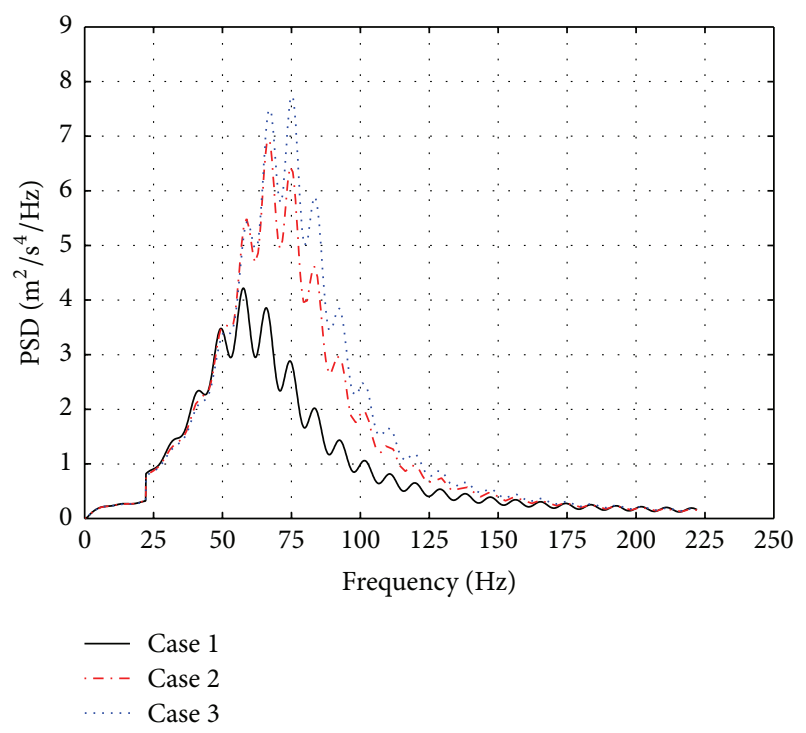

FIGURE 9: Power spectral density (PSD) of the vertical random vibration acceleration of a vehicle wheel due to the linear secant stiffness, the nonlinear frequency-dependent stiffness, and the nonlinear amplitude- and frequency-dependent stiffness of rail pads.

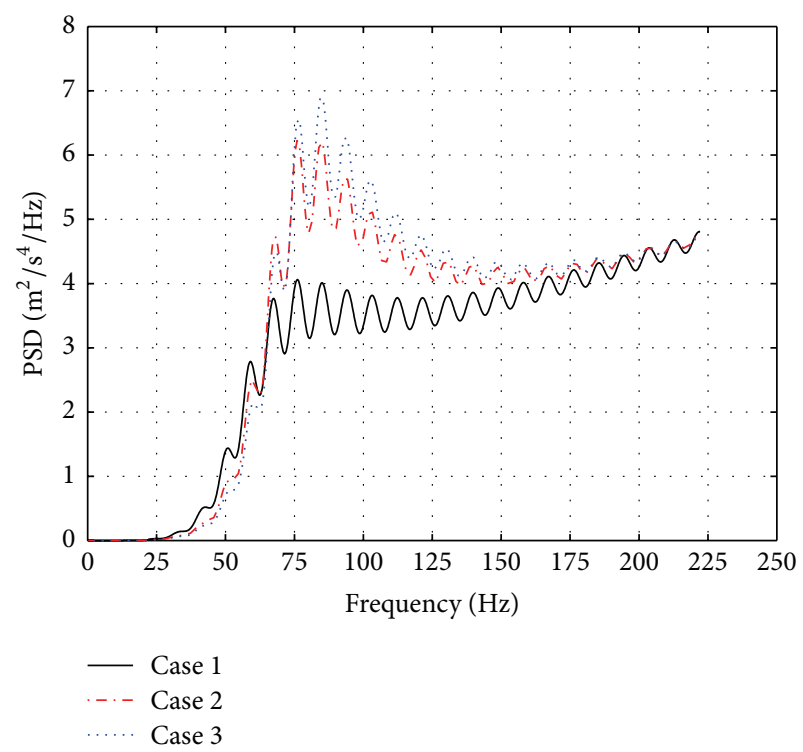

FIgure 10: Power spectral density (PSD) of the vertical random vibration acceleration of a steel rail due to the linear secant stiffness, the nonlinear frequency-dependent stiffness, and the nonlinear amplitude- and frequency-dependent stiffness of rail pads.

4.3.2. PSD of the Vertical Random Vibration Acceleration of a Vehicle Bogie. Similarly, the calculated dominant frequency domain of vehicle bogie in this paper also accords with the summary about the actual vibration generated by railway in [40]. It can be also observed from Figure 8 that the difference between the vertical random vibration responses of a vehicle bogie for the three cases is fairly small (within $20 \mathrm{~Hz}$ ) and yet the discrepancy for the responses in the three cases at frequencies of $20 \sim 150 \mathrm{~Hz}$ cannot be ignored. 
Upon further observation, it is found that, within the frequency scope of $20 \sim 50 \mathrm{~Hz}$, the vertical random vibration responses of the vehicle bogie in Case 1 are highest, followed by those in Case 2, with the responses in Case 3 being the lowest. For example, the PSD of the vertical random vibration acceleration of the vehicle bogie is $0.087 \mathrm{~m}^{2} / \mathrm{s}^{4} / \mathrm{Hz}$ at $37 \mathrm{~Hz}$ (point " $\mathrm{A}$ " in Figure 8) for Case 1, while the PSDs of the vertical random vibration acceleration of vehicle bogie at the same frequency in Cases 2 and 3 are $93.1 \%$ and $90.8 \%$ of the PSD in Case 1, respectively. However, in the frequency range of $50 \sim 150 \mathrm{~Hz}$, the results show the opposite trend, with the highest vertical random vibration responses of a vehicle obtained in Case 3 and the lowest responses obtained in Case 1. For instance, the PSD of the vertical random vibration acceleration of the vehicle bogie is $0.12 \mathrm{~m}^{2} / \mathrm{s}^{4} / \mathrm{Hz}$ at 73.7 Hz (point " $\mathrm{B}$ " in Figure 8) for Case 3, while the PSDs of the vertical random vibration acceleration of a vehicle bogie at the same frequency in Cases 2 and 1 are $83.3 \%$ and $37.0 \%$ of the PSD in Case 3, respectively. Obviously, in the case scenarios presented in this paper, the nonlinear frequency-dependent stiffness or the nonlinear amplitudeand frequency-dependent stiffness of rail pads principally enhances the random vibration levels of the vehicle bogie in frequencies of $50 \sim 150 \mathrm{~Hz}$, slightly reduces these responses at frequencies of $20 \sim 50 \mathrm{~Hz}$, and has no influence on these responses whatsoever at frequencies below $20 \mathrm{~Hz}$.

Due to the little effect of the three types of rail pad stiffness on the random vibrations at frequencies of $20 \sim 50 \mathrm{~Hz}$, the random vibrations at frequencies higher than $50 \mathrm{~Hz}$ are the subsequent focus in this study.

4.3.3. PSD of the Vertical Random Vibration Acceleration of a Vehicle Wheel. It is clear from Figure 9 that the vertical dominant random vibration accelerations of a vehicle wheel are mostly distributed in the frequency range of $0 \sim 150 \mathrm{~Hz}$.

It is found that the dominant frequency of vertical random vibration acceleration of vehicle wheel is $57.6 \mathrm{~Hz}$, which has a corresponding maximal PSD of $4.2 \mathrm{~m}^{2} / \mathrm{s}^{4} / \mathrm{Hz}$ in frequency domain in Case 1. In Case 2, the maximal PSD of vertical random vibration acceleration of vehicle wheel increases to $7.0 \mathrm{~m}^{2} / \mathrm{s}^{4} / \mathrm{Hz}$ which is 1.7 times the maximal PSD for Case 1; the corresponding dominant frequency also rises to $66.7 \mathrm{~Hz}$ which is $9.1 \mathrm{~Hz}$ higher than the dominant frequency in Case 1. Compared with Case 2, the maximal PSD of vertical random vibration acceleration of the vehicle wheel further increases by about $10 \%$ to become $7.8 \mathrm{~m}^{2} / \mathrm{s}^{4} / \mathrm{Hz}$ in Case 3, and the corresponding dominant frequency further rises by $8.4 \mathrm{~Hz}$ to become $75.1 \mathrm{~Hz}$. It can be concluded that the nonlinear frequency-dependent stiffness or the nonlinear amplitude- and frequency-dependent stiffness of rail pads not only increases the frequency-domain amplitudes of random vibration responses of the vehicle wheel, in a certain frequency domain $(50 \sim 150 \mathrm{~Hz}$ in the cases considered in this paper), but also moves the frequency-distribution of random vibration responses of the vehicle wheel to shift to the higher frequencies.

4.3.4. PSD of the Vertical Random Vibration Acceleration of a Steel Rail. It can be seen from Figure 10 that the vertical dominant random vibration accelerations of a steel rail are mostly above $50 \mathrm{~Hz}$ and the sensitive frequency domain influenced by three types of the stiffness of rail pads mainly occurs at frequencies in the range of $20 \sim 200 \mathrm{~Hz}$, particularly in the frequencies between 65 and $185 \mathrm{~Hz}$.

Similar to the variation of random vibration responses in a vehicle wheel with three types of the stiffness of rail pads, the influence of the nonlinear amplitude- and frequencydependent stiffness of rail pads on the random vibration responses of steel rail is the most conspicuous within the frequency scope of $65 \sim 185 \mathrm{~Hz}$, the influence of the nonlinear frequency-dependent stiffness of rail pads is secondary, and yet the influence of the linear secant stiffness of rail pads is relatively minimal.

In the three cases presented in this paper, the maximal PSD of vertical random vibration acceleration of the steel rail is $4.1 \mathrm{~m}^{2} / \mathrm{s}^{4} / \mathrm{Hz}$ with a dominant frequency of $76.1 \mathrm{~Hz}$ in Case 1. The maximal PSDs of vertical random vibration acceleration of a steel rail and their corresponding dominant frequencies increase to $6.2 \mathrm{~m}^{2} / \mathrm{s}^{4} / \mathrm{Hz}$ at $84.7 \mathrm{~Hz}$ in Case 2 and to $6.9 \mathrm{~m}^{2} / \mathrm{s}^{4} / \mathrm{Hz}$ at $85.0 \mathrm{~Hz}$ in Case 3, respectively. It is concluded that, contrasted with the linear secant stiffness, both the nonlinear frequency-dependent stiffness and the nonlinear amplitude- and frequency-dependent stiffness of rail pads significantly enlarge the random vibration of the vehicle wheel and steel rail in a certain frequency range $(65 \sim 150 \mathrm{~Hz}$ in the calculation example presented in this paper). Moreover, the effect of the nonlinear amplitude- and frequency-dependent stiffness of rail pads is obviously more significant than the influence of the nonlinear frequencydependent stiffness of rail pads.

\section{Conclusions}

Using rail pads of Thermoplastic Polyurethane Elastomer (TPE) usually used in Chinese subway fasteners as an example, the relationship between the static loads of TPE rail pads and their corresponding compressive deformations was measured with the universal testing machine. The nonlinear static analysis with application of a rail-fastener FEM was performed to quantify the compressive deformations of rail pads and their corresponding static stiffness under the static vehicle weight and the preload of rail fasteners. Next, based on the nonlinear static results of the railfastener system, the effect of the linear secant stiffness, the nonlinear frequency-dependent stiffness, and the nonlinear amplitude- and frequency-dependent stiffness of rail pads on the frequency-domain random vibration responses of vehicle body, bogie, wheel, and steel rail was investigated. According to the results presented in this study, some conclusions and suggestions are summarized as follows:

(1) The relationship between the static loads of TPE rail pads and their corresponding compressive deformations as measured with the universal testing machine is apparently nonlinear. With application of the nonlinear static FEM of a rail-fastener system, it can be found that the static stiffness of TPE rail pads is $19.1 \mathrm{kN} / \mathrm{mm}$ under a rail-fastener preload of $20 \mathrm{kN}$, 
and the maximum static stiffness of TPE rail pads is $37.9 \mathrm{kN} / \mathrm{mm}$ under both a vehicle weight of $640 \mathrm{kN}$ and rail fasteners preload of $20 \mathrm{kN}$. However, in previous research, the linear secant static stiffness of TPE rail pads was found to be $26.7 \mathrm{kN} / \mathrm{mm}$, which is apparently different from the actual nonlinear static stiffness. Therefore, since the rail pads have a strong nonlinear feature, it is unreasonable to use the linear secant stiffness without considering the variation of rail pad stiffness with the external load amounts.

(2) The random vibration responses in a vehicle-track coupled system demonstrate that the influence of the variation in stiffness of rail pads on the vertical random vibration of the vehicle body is negligible. Compared with the linear secant stiffness of rail pads, for the cases considered in this paper, the nonlinear frequency-dependent stiffness or the nonlinear amplitude- and frequency-dependent stiffness of rail pads has no influence whatsoever on the random vibration levels of the vehicle bogie, wheel, and steel rail in the frequencies below $20 \mathrm{~Hz}$, and it slightly reduces these responses in the frequency range between 20 and $50 \mathrm{~Hz}$. But it drastically enhances the random vibration levels at frequencies of $65 \sim 150 \mathrm{~Hz}$, which is none other than the dominant frequency domain of the environment vibration acceleration caused by low-speed urban railway.

(3) The nonlinear frequency-dependent stiffness or the nonlinear amplitude- and frequency-dependent stiffness of rail pads not only significantly enlarges the frequency-domain amplitudes of the random vibration responses of vehicle wheel and steel rail but also shifts the dominant frequency-distribution of the vehicle wheel and steel rail to the higher frequencies. Moreover, the effect of the nonlinear amplitudeand frequency-dependent stiffness of rail pads is more significant than the influence of the nonlinear frequency-dependent stiffness of rail pads.

In summary, it can be concluded that if there are polymer materials with the strong nonlinear stiffness in a vehicle or track system, the nonlinear amplitude- and frequencydependent stiffness of these materials must be taken into consideration in order to precisely predict the random vibration responses of vehicle-track coupled system.

\section{Competing Interests}

The authors declare that they have no competing interests.

\section{Funding}

This research was supported by National Natural Science Foundation of China (Grant no. 51578468), Fundamental Research Funds for the Central Universities of China (Grant no. 2682015CX087), National Outstanding Youth Science Foundation of China (Grant no. 51425804), and Joint Funds from both Chinese High-Speed Railway Company and the
National Natural Science Foundation of China (Grant nos. U1234201 and U1434201).

\section{Acknowledgments}

The authors would like to thank Chang-sheng Zhou, Yingchun Liang, and Zi-xuan Liu for their assistance in laboratory experiment and data processing.

\section{References}

[1] J. C. O. Nielsen, G. Lombaert, and S. François, "A hybrid model for prediction of ground-borne vibration due to discrete wheel/rail irregularities," Journal of Sound and Vibration, vol. 345, pp. 103-120, 2015.

[2] N. Triepaischajonsak and D. J. Thompson, "A hybrid modelling approach for predicting ground vibration from trains," Journal of Sound and Vibration, vol. 335, pp. 147-173, 2015.

[3] G. Kouroussis, N. Pauwels, P. Brux, C. Conti, and O. Verlinden, "A numerical analysis of the influence of tram characteristics and rail profile on railway traffic ground-borne noise and vibration in the Brussels Region," Science of the Total Environment, vol. 482-483, no. 1, pp. 452-460, 2014.

[4] G. Kouroussis, D. P. Connolly, G. Alexandrou, and K. Vogiatzis, "The effect of railway local irregularities on ground vibration," Transportation Research Part D: Transport and Environment, vol. 39, pp. 17-30, 2015.

[5] H. H. Hung, G. H. Chen, and Y. B. Yang, "Effect of railway roughness on soil vibrations due to moving trains by $2.5 \mathrm{D}$ finite/infinite element approach," Engineering Structures, vol. 57, pp. 254-266, 2013.

[6] X. Liu and W. Zhai, "Analysis of vertical dynamic wheel/rail interaction caused by polygonal wheels on high-speed trains," Wear, vol. 314, no. 1-2, pp. 282-290, 2014.

[7] Q. Li, Y. L. Xu, and D. J. Wu, "Concrete bridge-borne lowfrequency noise simulation based on traintrackbridge dynamic interaction," Journal of Sound and Vibration, vol. 331, no. 10, pp. 2457-2470, 2012.

[8] G. Degrande, M. Schevenels, P. Chatterjee et al., "Vibrations due to a test train at variable speeds in a deep bored tunnel embedded in London clay," Journal of Sound and Vibration, vol. 293, no. 3-5, pp. 626-644, 2006.

[9] D. P. Connolly, P. Alves Costa, G. Kouroussis, P. Galvin, P. K. Woodward, and O. Laghrouche, "Large scale international testing of railway ground vibrations across Europe," Soil Dynamics and Earthquake Engineering, vol. 71, pp. 1-12, 2015.

[10] W. M. Zhai, K. Y. Wang, and J. H. Lin, "Modelling and experiment of railway ballast vibrations," Journal of Sound and Vibration, vol. 270, no. 4-5, pp. 673-683, 2004.

[11] S. Falomi, M. Malvezzi, and E. Meli, "Multibody modeling of railway vehicles: innovative algorithms for the detection of wheel-rail contact points," Wear, vol. 271, no. 1-2, pp. 453-461, 2011.

[12] M. Kassner, "Fatigue strength analysis of a welded railway vehicle structure by different methods," International Journal of Fatigue, vol. 34, no. 1, pp. 103-111, 2012.

[13] K. D. Vo, H. T. Zhu, A. K. Tieu, and P. B. Kosasih, "FE method to predict damage formation on curved track for various worn status of wheel/rail profiles," Wear, vol. 322-323, pp. 61-75, 2015.

[14] F. Lu, D. Kennedy, F. W. Williams, and J. H. Lin, "Symplectic analysis of vertical random vibration for coupled vehicle-track 
systems," Journal of Sound and Vibration, vol. 317, no. 1-2, pp. 236-249, 2008.

[15] Y.-W. Zhang, Y. Zhao, J.-H. Lin, W. P. Howson, and F. W. Williams, "A general symplectic method for the response analysis of infinitely periodic structures subjected to random excitations," Latin American Journal of Solids and Structures, vol. 9, no. 5, pp. 569-579, 2012.

[16] J. Zhang, Q. Gao, S. J. Tan, and W. X. Zhong, "A precise integration method for solving coupled vehicle-track dynamics with nonlinear wheel-rail contact," Journal of Sound and Vibration, vol. 331, no. 21, pp. 4763-4773, 2012.

[17] K. D. Vo, A. K. Tieu, H. T. Zhu, and P. B. Kosasih, "A 3D dynamic model to investigate wheel-rail contact under high and low adhesion," International Journal of Mechanical Sciences, vol. 85, pp. 63-75, 2014.

[18] E. Poveda, R. C. Yu, J. C. Lancha, and G. Ruiz, "A numerical study on the fatigue life design of concrete slabs for railway tracks," Engineering Structures, vol. 100, pp. 455-467, 2015.

[19] G. Saussine, C. Cholet, P. E. Gautier et al., "Modelling ballast behavior under dynamic loading. Part 1: a 2D polygonal discrete element method approach," Computer Methods in Applied Mechanics and Engineering, vol. 195, no. 19-22, pp. 2841-2859, 2006.

[20] H. Huang and S. Chrismer, "Discrete element modeling of ballast settlement under trains moving at 'critical speeds"' Construction and Building Materials, vol. 38, pp. 994-1000, 2013.

[21] E. Meli, S. Magheri, and M. Malvezzi, "Development and implementation of a differential elastic wheel-rail contact model for multibody applications," Vehicle System Dynamics, vol. 49, no. 6, pp. 969-1001, 2011.

[22] E. Meli and A. Ridolfi, "An innovative wheel-rail contact model for railway vehicles under degraded adhesion conditions," Multibody System Dynamics, vol. 33, no. 3, pp. 285-313, 2013.

[23] P. J. Remington, "Wheel/rail rolling noise, I: theoretical analysis," Journal of the Acoustical Society of America, vol. 81, no. 6, pp. 1805-1823, 1987.

[24] N. Zhang, H. Xia, W. W. Guo, and G. De Roeck, "A vehiclebridge linear interaction model and its validation," International Journal of Structural Stability and Dynamics, vol. 10, no. 2, pp. 335-361, 2010.

[25] K. Abe, Y. Chida, P. E. Balde Quinay, and K. Koro, "Dynamic instability of a wheel moving on a discretely supported infinite rail," Journal of Sound and Vibration, no. 15, pp. 3413-3427, 2014.

[26] A. Johansson, J. C. O. Nielsen, R. Bolmsvik, A. Karlström, and R. Lundén, "Under sleeper pads_-influence on dynamic traintrack interaction," Wear, vol. 265, no. 9-10, pp. 1479-1487, 2008.

[27] M. Sol-Sánchez, F. Moreno-Navarro, and M. C. Rubio-Gámez, "Viability of using end-of-life tire pads as under sleeper pads in railway," Construction and Building Materials, vol. 64, pp. 150156, 2014.

[28] T. Xin and L. Gao, "Reducing slab track vibration into bridge using elastic materials in high speed railway," Journal of Sound and Vibration, vol. 330, no. 10, pp. 2237-2248, 2011.

[29] H. Saurenman and J. Phillips, "In-service tests of the effectiveness of vibration control measures on the BART rail transit system," Journal of Sound and Vibration, vol. 293, no. 3-5, pp. 888-900, 2006.

[30] J. Maes, H. Sol, and P. Guillaume, "Measurements of the dynamic railpad properties," Journal of Sound and Vibration, vol. 293, no. 3-5, pp. 557-565, 2006.
[31] I. A. Carrascal, J. A. Casado, J. A. Polanco, and F. GutiérrezSolana, "Dynamic behaviour of railway fastening setting pads," Engineering Failure Analysis, vol. 14, no. 2, pp. 364-373, 2007.

[32] Y. Luo, Y. Liu, and H. P. Yin, "Numerical investigation of nonlinear properties of a rubber absorber in rail fastening systems," International Journal of Mechanical Sciences, vol. 69, pp. 107-113, 2013.

[33] S. Kaewunruen and A. M. Remennikov, "An alternative rail pad tester for measuring dynamic properties of rail pads under large preloads," Experimental Mechanics, vol. 48, no. 1, pp. 55-64, 2008.

[34] K. Wei, P. Wang, F. Yang, and J. Xiao, "The effect of the frequency-dependent stiffness of rail pad on the environment vibrations induced by subway train running in tunnel," Proceedings of the Institution of Mechanical Engineers Part F Journal of Rail and Rapid Transit, vol. 230, no. 3, pp. 697-708, 2014.

[35] S. Zhu, C. Cai, and P. D. Spanos, "A nonlinear and fractional derivative viscoelastic model for rail pads in the dynamic analysis of coupled vehicle-slab track systems," Journal of Sound and Vibration, vol. 335, pp. 304-320, 2015.

[36] GB/T, "The state administration of quality supervision, inspection and quarantine of People's Republic of China, national standardization management committee of China. Elastic plate in fastener system of Rail transit," Grant No. GB/T 21527-2008, Standards Press of China, Beijing, China, 2008 (Chinese).

[37] A. Hamid and T. L. Yang, "Analytical description of trackgeometry vibrations," Transportation Research Record, vol. 838, pp. 19-26, 1981.

[38] D. J. Thompson and J. W. Verheij, “The dynamic behaviour of rail fasteners at high frequencies," Applied Acoustics, vol. 52, no. 1, pp. 1-17, 1997.

[39] A. Fenander, "Frequency dependent stiffness and damping of railpads," Proceedings of the Institution of Mechanical Engineers, Part F: Journal of Rail and Rapid Transit, vol. 211, no. 1, pp. 51-62, 1997.

[40] G. Kouroussis, D. Connolly, and O. Verlinden, "Railwayinduced ground vibrations-a review of vehicle effects," International Journal of Rail Transportation, vol. 2, no. 2, pp. 69-110, 2014. 


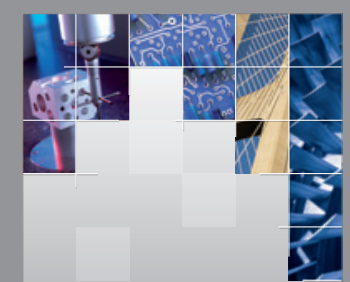

\section{Enfincering}
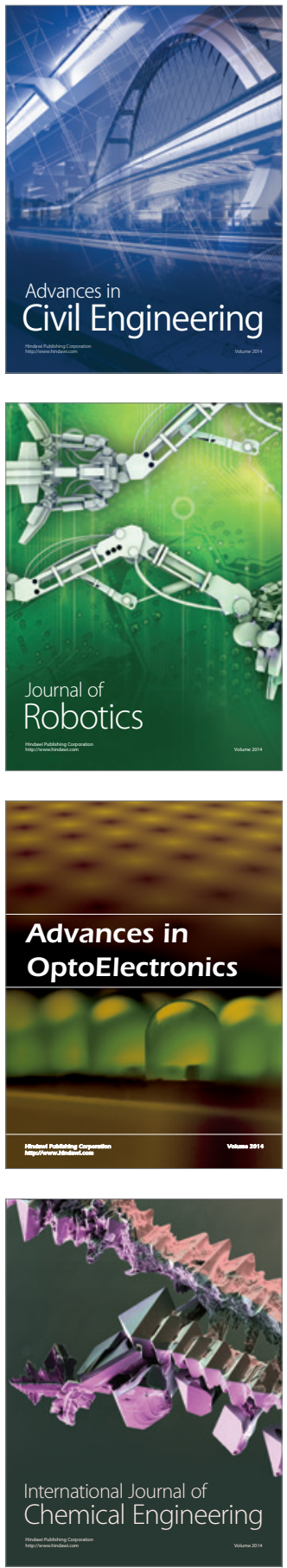

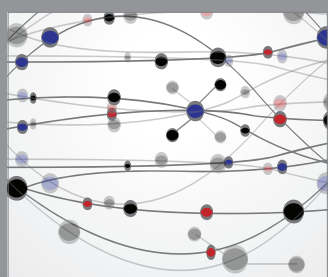

The Scientific World Journal

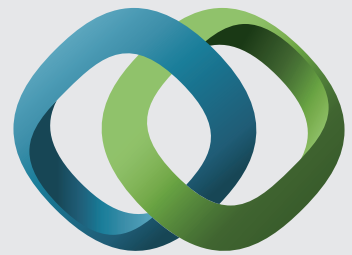

\section{Hindawi}

Submit your manuscripts at

http://www.hindawi.com
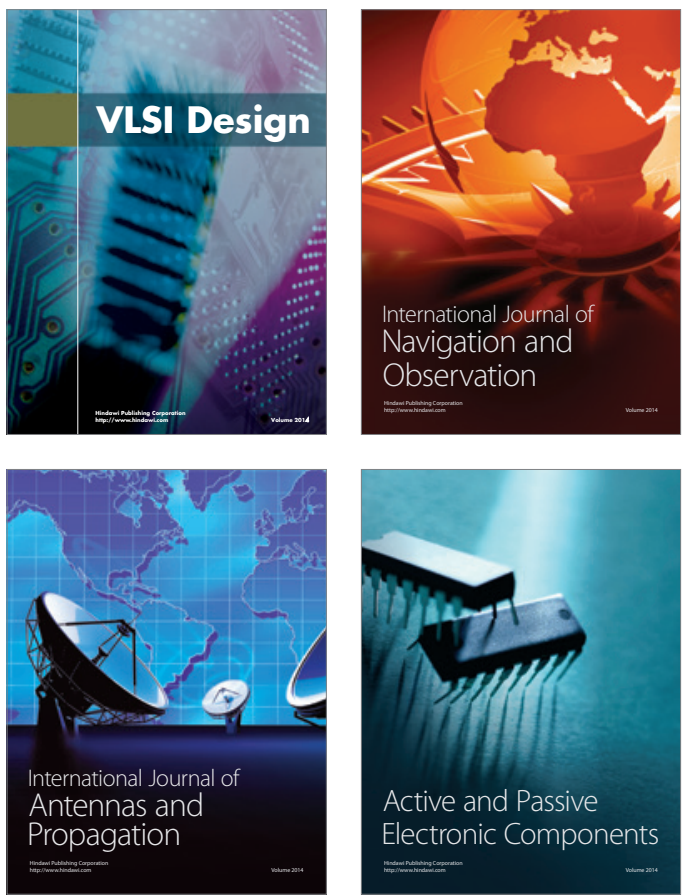
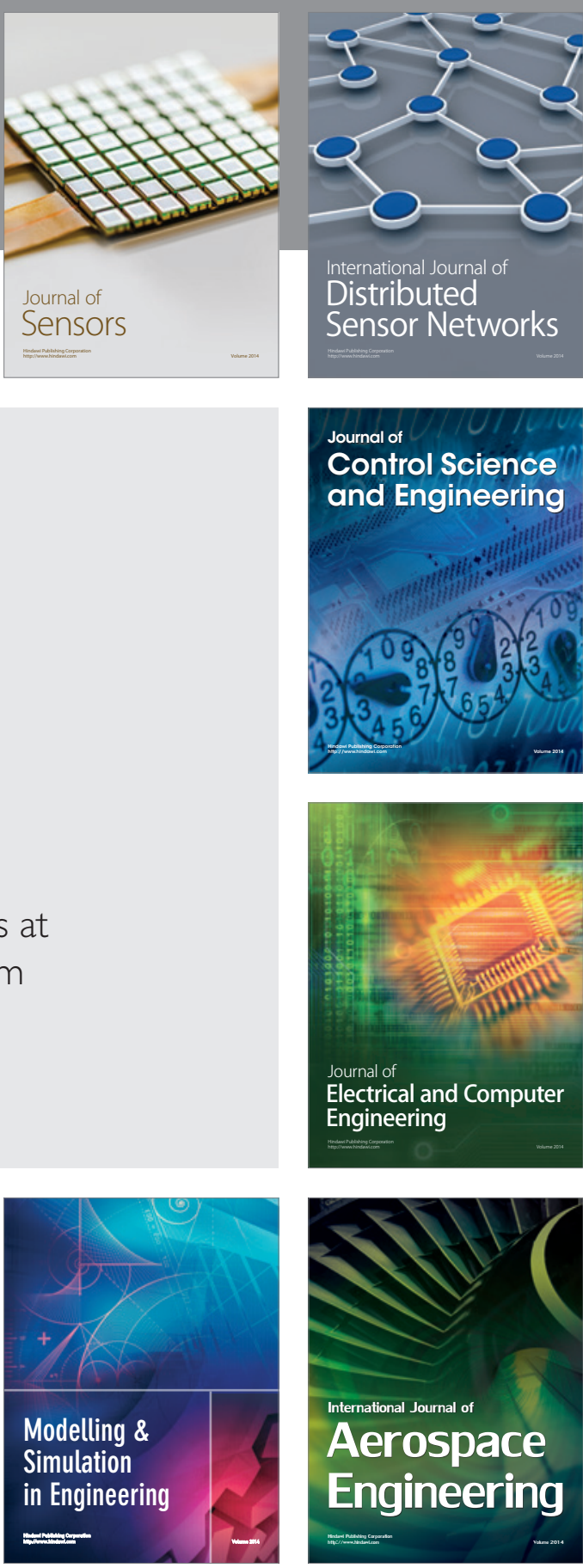

International Journal of

Distributed

Sensor Networks

Journal of

Control Science

and Engineering
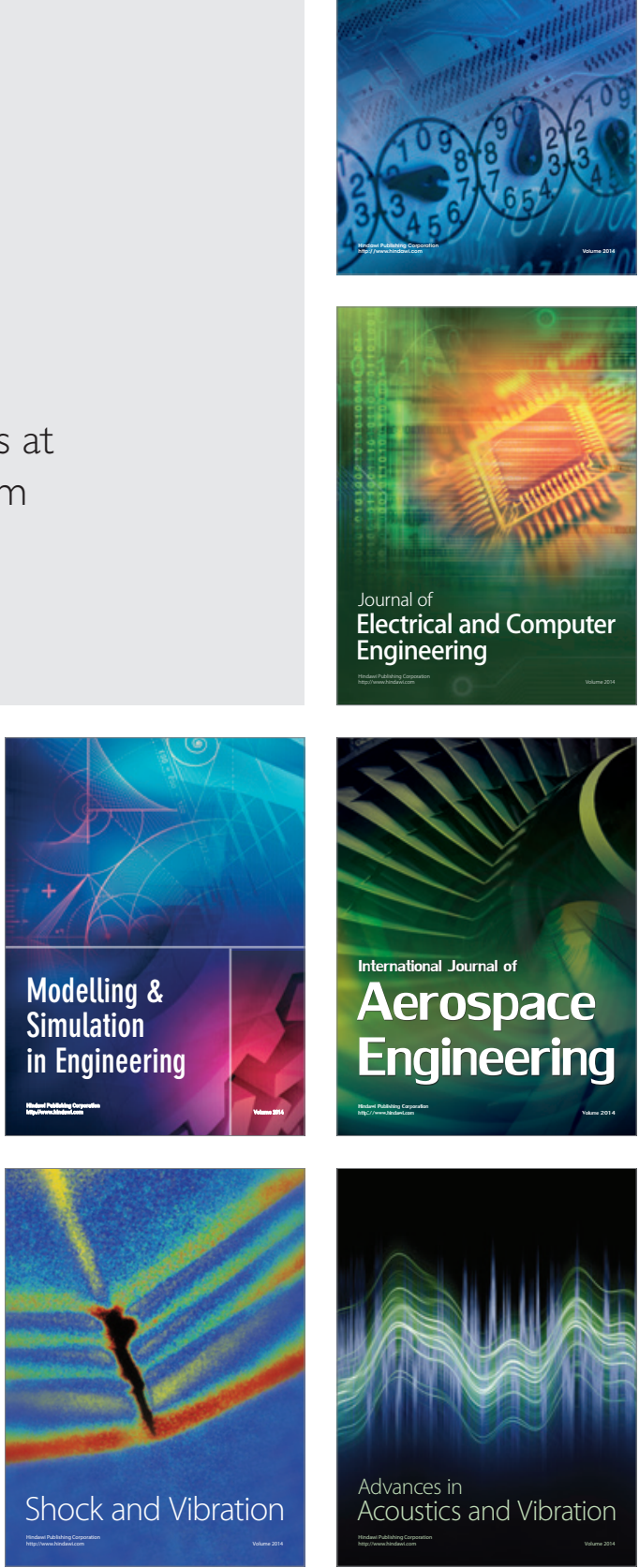